\title{
Femoral exostosis a cause of Popliteal Artery Pseudo aneurysm: Case report and review of the literature
}

\author{
Lamiae Bouimetarhan, Othman Ayouche, Ittimade Nassar
}

\begin{abstract}
Introduction: Osteochondromas are benign bone tumors. They can be asymptomatic or damage adjacent structures and and can cause various types of complications among them pseudo aneurysms, which are uncommon consequences of this pathologic osseous growth. The advent of new radiologic modalities has allowed for early diagnostics and treatment of these entities. Case Report: We report the case of a 29-year-old female, with no history of chronic disease, who consulted for a throbbing sensation behind the knee and a lump mass in the popliteal fossa. We conducted a doppler ultrasound and a CT-angiography, which demonstrated a popliteal artery aneurysm complicating an osteochondroma. A surgery, was done with no complication in the 24 months follow-up. Conclusion: Early diagnosis followed by surgical resection is the mainstay of management popliteal artery aneurysm complicating osteochondromas. CT angiography is the modality of choice for the detection and evaluation of osteochondromas vascular complications.
\end{abstract}

Keywords: Bone exostosis, Computed tomography, Popliteal artery, Pseudo aneurysm, Ultrasound

Lamiae Bouimetarhan ${ }^{1}$, Othman Ayouche ${ }^{1}$, Ittimade Nassar Affiliations: ${ }^{1}$ Central Radiology Department, Ibn Sina Hospital, Mohamed V University, Rabat, Morocco.

Corresponding Author: Lamiae Bouimetarhan, Central Radiology Department, Ibn Sina Hospital, Mohamed V University, Rabat, Morocco; Email: lamiae.bmtrn@hotmail.com

Received: 14 May 2018

Accepted: 19 June 2018

Published: 18 July 2018

\section{How to cite this article}

Bouimetarhan L, Ayouche O, Nassar I. Femoral exostosis a cause of Popliteal Artery Pseudo aneurysm: Case report and review of the literature. Int J Case Rep Images 2018;9:100936Z01LB2018.

Article ID: 100936Zo1LB2018

$* * * * * * * * *$

doi: 10.5348/100936Zo1LB2018CR

\section{INTRODUCTION}

Osteochondromas are the most common benign tumors of the bones developing during the adolescence and occurring most commonly in the lower limb and more specifically at the distal femoral metaphysis [1]. It occurs in (1 to $2 \%$ ) of the population [2]. Vascular complications would result from "trapping" vascular structures by the adjacent exostosis. The involvement of the popliteal artery is the most common vascular complications [3]. Arterial pseudo aneurysmsare encapsulated hematomas communicating with the lumen of a ruptured artery.

Itsformation mechanism, associated with bone exostoses, has been well described in the literature. We report a case of a 29-year-old female, witha solitary exostosis of the left femur who presented a pseudo aneurysm of the popliteal artery, who then underwent a duplex scan and a CT-angiography for diagnosis after which she was treated surgically.

\section{CASE REPORT}

A 29-year-old female, with no history of chronic disease, consulted for a throbbing sensation behind the knee. Physical examination demonstrated the presence of a lump mass in the popliteal fossa, which measured $1 \mathrm{~cm}$. The examination found a painless pulsatile mass of the 


\section{EDORiUM Journals}

popliteal fossa, with no associated neurological deficit. Dorsalis pedis (DP) and posterior tibial (PT) pulses were conserved.

Doppler ultrasound showed a pseudo aneurysm of the left popliteal artery associated with peripheralthrombosis (Figure 1). CT angiography revealed the presence of a Left popliteal artery saccular aneurysmpartially thrombosed measuring 32x30 mm with a neck measuring $03 \mathrm{~mm}$ and a solitary femoral exostosis on the distal end (Figures 2 and 3). There was no signs of popliteal vein compression. The patient then underwent a same time surgery for the aneurysm and a resection of the osteochondroma. The steps of surgical techniques were: A posterior double skin incision supra and infra articular was performed which allowed for the clamping of the artery. The patient underwenta flattening of the aneurysm and restoration of vascular continuity with an end-to-endanastomosis. After the control of the aneurysm, a resection of the osteochondroma was performed. Follow up sonography evaluated for post-operative ischemia or thrombosis, which demonstrated the permeability of the popliteal pedicle. The patient returned home two weeks after his surgery. Histological examination of the exostotic tissues had shown normal bone tissue with no sign of malignant degeneration. After surgery the patient's vascular status was regular, with no signs of deficit. No vascular complications were noted during our 24 months followup, which consisted of a physical exam, and a duplex scan.

\section{DISCUSSION}

Osteochondromas are frequent benign bone tumors. It develops during adolescence. Its most common site is the distal femoral metaphysis $[1,2]$. It is among the "let alone bone lesions".But in some cases surgical treatment might be prompted. Vascular complications, observed in (11\%) of cases, would result from «trapping» vascular structures by adjacent exostosis [3]. In fact, osteochondromas have a protective cartilaginous cap, which ossifies at the end of the growth period with the epiphyseal fusion. The resorption of this cartilaginous cap might happen in young adults, leaving sharp bone, which can be a source of repetitive micro traumatism to the arteries wall resulting in complications such as pseudoaneurysms or thrombosis [2].

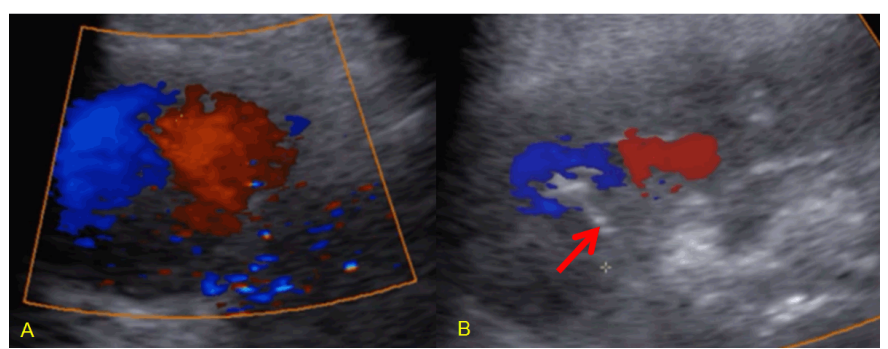

Figure 1: Doppler ultra-sonography of the popliteal fossa (A) cystic structure with the "yin-yang sign" (B) associated to a distal end femoral exostosis (arrow).

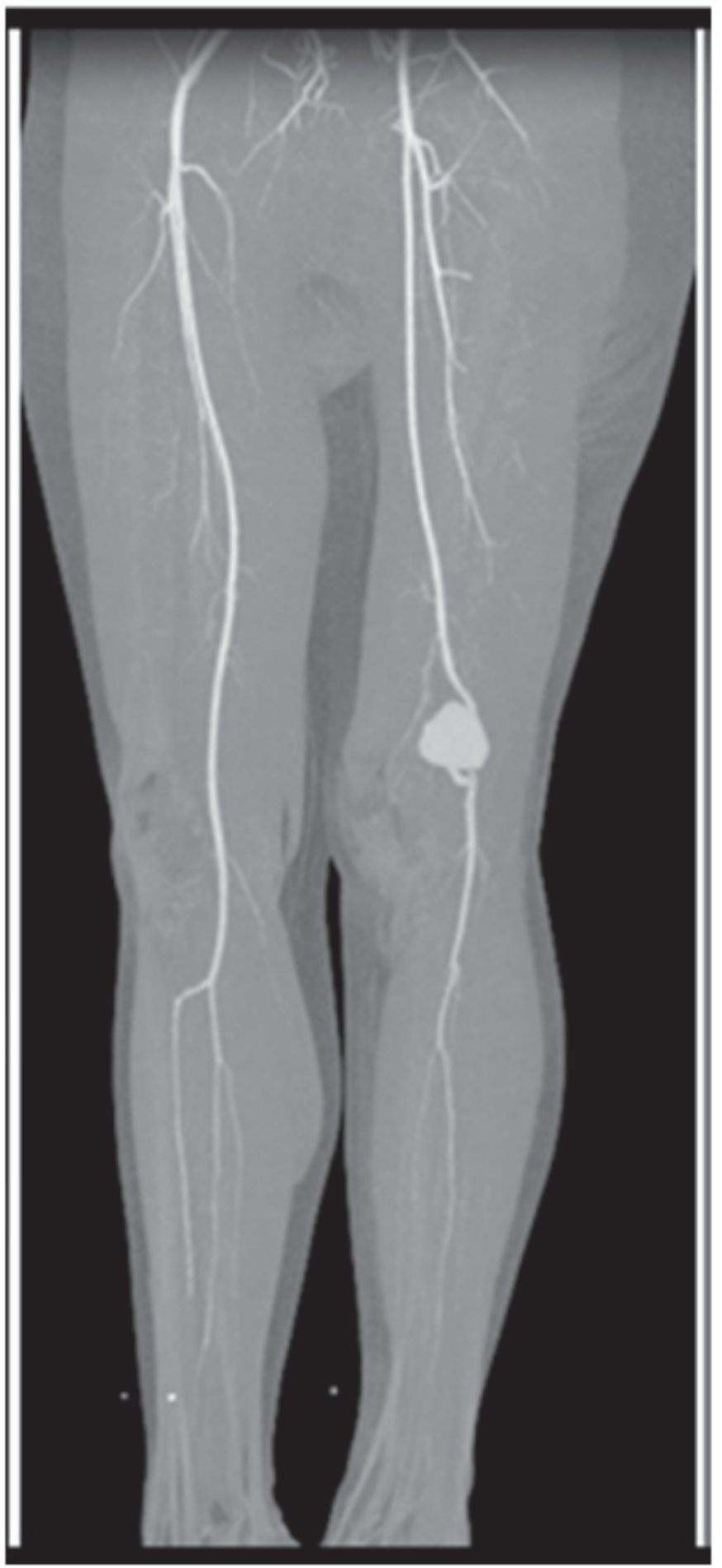

Figure 2: Coronal view CT angiography: Left popliteal artery saccular aneurysm.

The involvement of the popliteal artery is the most common site of vascular complications (91\% of cases) due to itsproximity to the distal femur and proximal tibia, the most common sites of osteochondroma formation [4].

In its popliteal location, exostosis is often asymptomatic but may be revealed by more specific symptoms, such as chronicpainand kneeedema. 


\section{EDORiUM Journals}

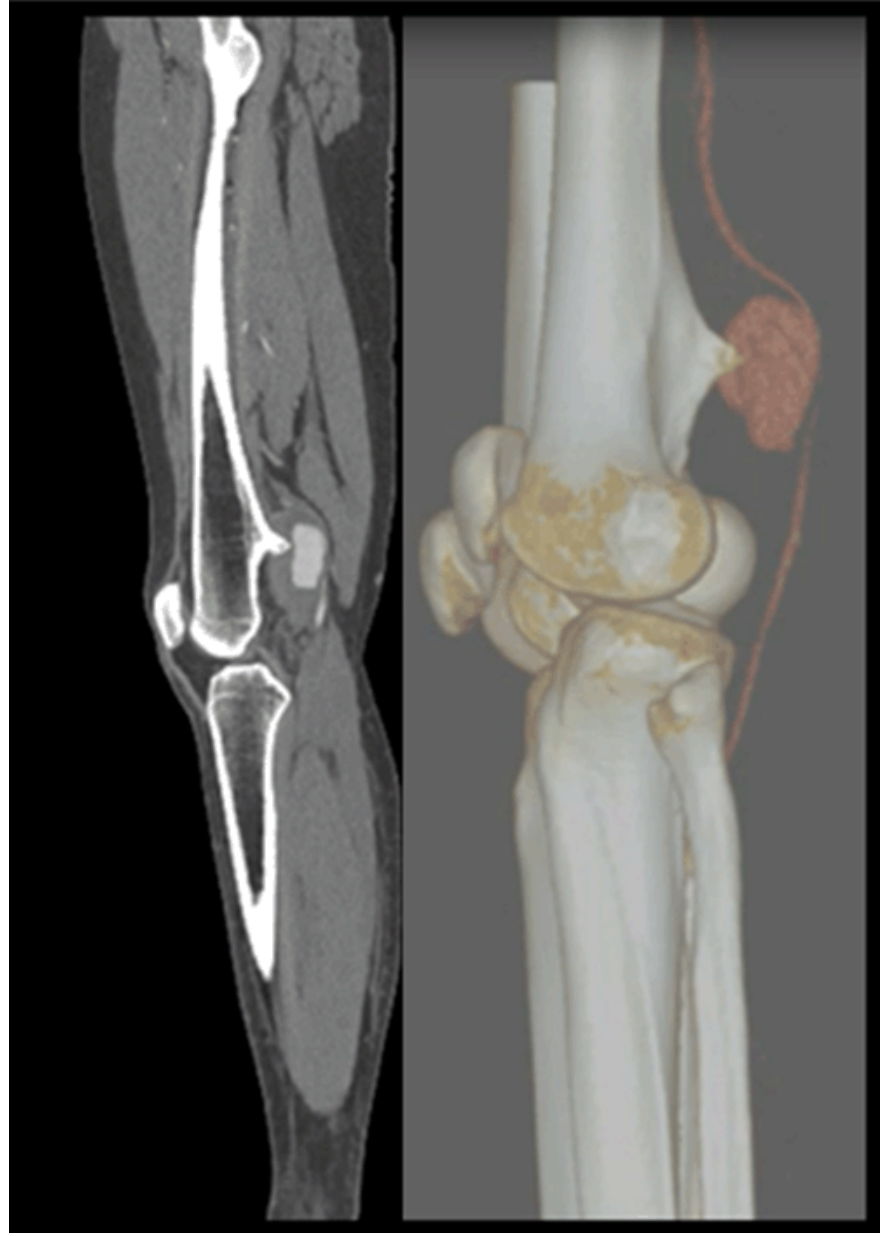

Figure 3: Sagittal MIP and VRT, C+ arterial phase: Partially thrombosed left popliteal artery saccular aneurysm and a distal solitary femoral exostosis.

In other instances, vascular complications may be revealed by more specific clinical manifestations including painful pulsatile mass associated with hematoma, functional abnormalities, edema, neuropathic pain, phlebitis and acute distal ischemia [5].

The role of radiology is to diagnose osteochondromas and to evaluate its cartilaginous cap, its relationship to the adjacent structures as well as the prevention of further complications.

Radiological features of osteochondromas are often pathognomonic; the protuberance is composed of cortical and medullary bone with an overlying hyaline cartilage cap in continuity with the underlying parent bone cortex [6].

Doppler US helps establish the diagnosis. A typical swirling motion called the "yin-yang sign" characterizes blood flow within a cystic structure. However, this flow pattern could be seen in saccular aneurysms, so a diagnosis made on this finding alone may prove to be inaccurate.

The diagnosis hallmark is the demonstration of a communicating channel (neck) between the sac and the feeding artery with a "to-and-fro" waveform at duplex Doppler US.

Sonography also play a role in the measurement of the cartilaginous capthickness, which appears as an hypoechoic mass adjacent to the exostosis. CT angiography is a valuable diagnostic tool for the detection of vascular complications: Non-enhanced CT scans show a low-density ovoid or round well-defined structure contiguous to the donor artery.

A high density (hemorrhage) adjacent to the pseudoaneurysmindicatesrupture, which vary in attenuation depending on its chronology. After the administration of Contrast material, we observed the total filling of the sac and the communication with the donor artery [7]. A finding, absent in case of total thrombosis or stenosis of the pseudo aneurysm.

Endovascular treatment is comprised of image-guided occlusion of the pseudo aneurysm with coils it conserve its indication for aneurysms with a narrow neck. However, this method of treatment is not recommended for this age group due to its short durationand the possibility of recurrence [8, 9].

Surgical vascular reconstruction and excision of the adjacent osteochondroma is the treatment of choice in symptomatic patients.Urgent surgical treatment of vascular complicationsis needed in order to prevent the occurrence of irreversible damages such as distal vessel occlusion or pulmonary embolism.

In our case, the juxta articular localization, the patient young age, the wide collar of the pseudoaneurysm and especially the need for a same-time tumor resection prompted the need for a surgical treatment. Follow-up exams are mainly composed of plain radiographs for the bone lesions and US for distal vascular complications [10]. In our case, no vascular complications were noted during our 24 months follow-up.

\section{CONCLUSION}

Pseudoaneurysms are common vascular abnormalities. The advent of new non-invasive diagnosticimaging techniques with increased sensitivity for asymptomatic disease has led to more frequent diagnostics. Although image guided methods are recommended for peripheral arteries aneurysms. In our casesurgical treatment was prompted for the treatment of bony lesions.

\section{REFERENCES}

1. Murphey MD, Choi JJ, Kransdorf MJ, Flemming DJ, Gannon FH.Imaging of osteochondroma:Variants and complications with radiologic-pathologic correlation. Radiographics 2000 Sep-Oct;20(5):1407-34.

2. Lesser A, Greely C. Arterio-venous fistula due to femoral osteochondroma. JAMA 1958;167:1830-2. 
www.ijcasereportsandimages.com

3. Eschelman DJ, Gardiner GA Jr, Deely DM. Osteochondroma: An unusual cause of vascular disease in young adults. J Vasc Interv Radiol 1995 Jul-Aug;6(4):605-13.

4. Wicklund CL, Pauli RM, Johnston D, Hecht JT. Natural history study of hereditary multiple exostoses. Am J Med Genet 1995 Jan 2;55(1):43-6.

5. Leve L, Kalideen JM. Popliteal false aneurysm complicating osteochondroma: A case report. S Afr Med J 1979 Jun 23;55(26):1087-8.

6. Woertler K, Lindner N, Gosheger G, Brinkschmidt C, Heindel W. Osteochondroma: MR imaging of tumorrelated complications. Eur Radiol 2000;10(5):83240.

7. Knisely BL, Mastey LA, Collins J, Kuhlman JE. Imaging of cardiac transplantation complications. Radiographics. 1999 Mar-Apr;19(2):321-39.

8. Bullough PG, Vigorita VJ. Atlas of Orthopaedic Pathology with Clinical and Radiologic Correlations. London: Butterworths; 1984.

9. Anastasi GW, Wertheimer HM, Brown JR. Popliteal aneurysm with osteochondroma of the femur. Arch Surg 1963 Oct;87:636-9.

10. Ahmed Z, Desai M, Grewal PS, Hamilton G. Operative technique for the treatment of popliteal artery aneurysms. The Cochrane Library 2014.

$* * * * * * * * *$

\section{Author Contributions}

Lamiae Bouimetarhan - Acquisition of data, Drafting the article, Revising it critically for important intellectual content, Final approval of the version to be published
Othman Ayouche - Acquisition of data, Drafting the article, Revising it critically for important intellectual content, Final approval of the version to be published Ittimade Nassar - Acquisition of data, Drafting the article, Revising it critically for important intellectual content, Final approval of the version to be published

\section{Guarantor of Submission}

The corresponding author is the guarantor of submission.

\section{Source of Support \\ None}

\section{Consent Statement}

Written informed consent was obtained from the patient for publication of this case report.

\section{Conflict of Interest}

Authors declare no conflict of interest.

\section{Copyright}

(C) 2018 Lamiae Bouimetarhan et al. This article is distributed under the terms of Creative Commons Attribution License which permits unrestricted use, distribution and reproduction in any medium provided the original author(s) and original publisher are properly credited. Please see the copyright policy on the journal website for more information.
Access full text article on other devices

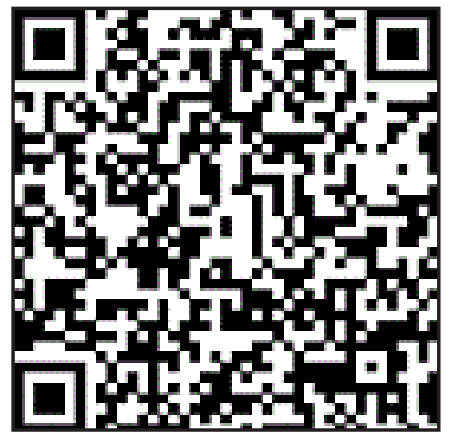

Access PDF of article on other devices

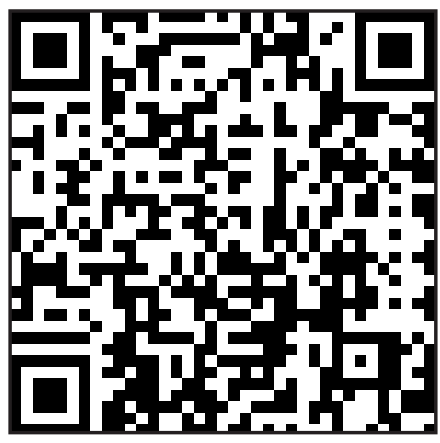

